\title{
DISCURSO CRÍTICO E IMAGENS DO ÍNDIO CONTEMPORÂNEO
}

\author{
Eloína Prati dos Santos ${ }^{1}$
}

\begin{abstract}
Resumo: Este texto mostra algumas das vozes críticas contemporâneas de indígenas dos Estados Unidos e do Canadá, com uma interface brasileira, constituindo uma amostra de obras que promovem uma desconstrução da imagem do índio persistente no imaginário americano através de um contra discurso que inclui terminologia e figuras ao mesmo tempo tradicionais e inovadoras.
\end{abstract}

Palavras-Chave: Crítica Ameríndia, Literatura Estadunidense, Literatura Canadense, Literatura Brasileira.

\begin{abstract}
The text presents some contemporary indigenous critical voices from the United States and Canada, with a Brazilian interface, constituting a sample of works which promote a deconstruction of the Indian image persistent in the American imagination through a counter discourse which includes terminology and figures, at one time, traditional and innovative.
\end{abstract}

Keywords: Amerindian Criticism, US American Literature, Canadian Literature, Brazilian Literature

Com poucas exceções, os romancistas indígenas - exemplos de índios que repudiaram seus enredos designados - em sua ficção, rejeitam o gótico americano com sua selva assombrada e carregada de culpa e o autóctone condenado, enfaticamente fazendo do índio o herói de outros destinos, outros enredos (Louis Owens) ${ }^{2}$.

Mais de quinhentos anos de resistência indígena ao colonialismo sugere que a luta não terá fim (Jean M. O'Brien) ${ }^{3}$.

A epígrafe, oriunda da introdução do livro de Owens, Outros destinos (1992), norteia o trabalho de mapear a voz critica indígena nos Estados Unidos e no Canadá, de que forma ela cria um vocabulário que permite ler a literatura indígena sob o ponto de vista das próprias

1 Universidade Federal do Rio Grande do Sul, Aposentada. PhD em Literaturas de Língua Inglesa. Endereço eletrônico: eloinaprati@gmail.com.

2 With few exceptions, American Indian novelists - examples of Indians who have repudiated their assigned plots - are in their fiction rejecting the American gothic style with its haunted, guilt-burdened wilderness as well as the doomed Native, emphatically making the Indian the hero of other destinies, other plots (1992, p. 18). As citações são de obras em inglês com traduções da autora.

3 More than five hundred years of Indian resistance to colonialism suggests that the struggle will not end (2010, p. 145). 
culturas nativas do continente Americano e oferece ao leitor euro-americano uma visão não canônica de obras de ficção nelas enraizadas. Leitura essa que é possível estender a exemplos recentes da literatura indígena brasileira.

A obra da historiadora Jean M. O'Brien (White Earth Ojibwe), Firsting and lasting. Writing Indians out of existence in New England (2010), demonstra como algumas obras recentes sobre o apagamento e o regate da memória indígena vêm constituindo uma contra memória americana, ainda em grande parte desconhecida da cultura main stream, apesar da visibilidade dos escritores indígenas estadunidenses e canadenses e de sua emergência consistente no Brasil.

Embora restritos à Nova Inglaterra, os processos descritos por O'Brian podem ser aplicados à maioria das colonizações nas várias regiões das três Américas. O levantamento realizado por ela enfoca apenas publicações históricas que contém "material indígena", dentro do período de 1810 a 1890, em Connecticut, Massachusetts e Rhode Island, um total de 447 textos. Embora os povos indígenas residentes nestas áreas na época da chegada dos primeiros colonizadores lá permanecessem duzentos anos depois, ela constata que para os não índios eles haviam sido extintos. Impressão ou crença facilmente contestada pelo relatório do Comissário para os Índios de Massachusetts, John Milton Earle, que lista as famílias e comunidades que ele havia encontrado no território por volta de 1850, e reforçada pelo fato de existirem comissões governamentais de Indian Affairs nos três estados na época (p. xii).

Essa atitude, que a autora chama de firsting, afirmava que os colonizadores instalaram na área as primeiras instituições e a ordem social. Ao lado de autores como Francis Parkman, George Brancroft, Henry Rowe Schoocraft, Henry Louis Morgan, James Fenimore Cooper, Lydia Maria Child, entre outros, as obras dos autores locais atingia um grande público leitor com histórias baseadas em fatos locais e sobre seus indígenas, cuja mensagem principal era a do vanishing Indian. ${ }^{4} \mathrm{O}$ tropo era tão disseminado que aparecia em comemorações, monumentos e discursos, que ela denomina de "narrativas de substituição" (lasting): dar nomes indígenas a ruas, escolas, dias comemorativos, criar uma arqueologia que coloca o indígena no passado e instala uma história de suplantação dos índios pelos não índios. O’Brien entende

4 A expressão tornou-se popular a partir de um filme de 1926, baseado no famoso romance de Zane Grey, um melodrama histórico sobre os maus tratos aos indígenas e sua habilidade de sobreviver às dificuldades impostas pelo governo, pelas dificuldades ambientais e intertribais. 
Pontos de Interrogação, v. 4, n. 2, jul./dez. 2014

Revista do Programa de Pós-Graduação em Crítica Cultural

Universidade do Estado da Bahia (UNEB), Campus II — Alagoinhas — BA

que esta atitude estabelecia que só os não indígenas eram modernos; a modernidade era negada aos índios, extintos no inconsciente da Nova Inglaterra. Esta imagem, engendrada por autores hoje obscuros e esquecidos, construiu um projeto ideológico que continua a "formar, limitar e inibir visões dos índios mesmo nos dias de hoje” (p. 55).

O’Brien oferece exemplos desta literatura nos Estados Unidos, como o clássico O último dos moicanos (1826), de Fenimore Cooper, romance histórico situado em 1757, onde os personagens indígenas Magua (um chefe Hurão) e Uncas (Moicano) morrem na última batalha, enquanto Hawkeye (o herói branco) comenta a situação trágica dos índios e lamenta a extinção dos Moicanos. Este é o tipo de estratégia retórica que ela chama de lasting, o clássico "o último dos (em branco)", que ela denomina de "purificação da paisagem" (p. 109). Outras estratégias adotadas eram registrar índios como negros e declarar os índios incapazes de mudar. Mas eles mudaram e sua literatura contemporânea espelha claramente esse processo de modernização que os integra à cultura do continente, que ainda resiste, incompreensivelmente, a admitir a rica contribuição cultural dos nativos americanos.

Em 1969, o prestigioso Prêmio Pulitzer ${ }^{5}$ foi atribuído pela primeira vez a um romance indígena, House made of dawn (1968), de N. Scott Momaday (Kiowa). Abel, o personagem central da obra, é uma clara referência bíblica ao arquétipo da vítima, mas a história foge da dicotomia índio contra branco, pois os algozes de Abel são Juan Fraga, um Tanoa, Tosamah, um irmão Kiowa e Martinez, um Chicano ou um índio mexicano. Embora os euro-americanos tenham sua parcela de culpa no drama de Abel, a obra é focada em sua busca de identidade, comum entre jovens índios que experimentaram a vida nas reservas e nos internatos governamentais $^{6}$. No caso de Momaday, rejeitado por sua própria tribo por ser filho ilegítimo, provavelmente de um índio Navajo, dá base à autoficção onde a crise de identidade situa-se em um universo distante dos padrões do "romance de protesto" esperado das minorias étnicas.

Em 1974 pela primeira vez o New York Times Book Review publicou uma resenha crítica de uma romance indígena, Winter in the blood (1974), de James Welch (Blackfeet/Gros

5 O primeiro Prêmio Pulitzer foi entregue em 1917. Administrado pela Universidade de Colúmbia (NY) reconhece obras de excelência em jornalismo, literatura e música.

6 A internação das crianças ameríndias em escolas do estado, principalmente nos Estados Unidos e no Canadá, era compulsória e lá passavam nove meses do ano longe de suas famílias e comunidades, falando apenas a língua europeia imposta, em violento plano de aculturação forçada que incluiu abuso psicológico, físico e sexual. 
Ventre), onde um protagonista sem nome transita entre as terras de sua mãe na reserva e os bares de Havre, Montana. Depois da infância marcada pela morte do irmão, atropelado aos 14 anos e a morte do pai, encontrado congelado após uma tempestade de neve, instala-se o "inverno em seu sangue". Ele consola-se com mulheres e brigas nos bares, em um caminho de autodestruição que rende uma narrativa tocante, mas de modo geral cômica. E como tal se insere perfeitamente na corrente pós-moderna da época, representada por Donald Barthelme, John Barth, Kurt Vonnegut, Philip Roth e outros. O humor de Welch vai do farsesco ao satírico e inclui escatologia para cortar o sentimentalismo de certas situações, ou seja, um humor proveniente da figura do trickster e essencialmente indígena.

O prêmio a Momaday e a presença de Welch na primeira página de um jornal de grande circulação em meados de 1970, colocam a literatura ameríndia dentro da cultura mainstream estadunidense de forma inequívoca e a voz indígena em competição com as demais, inclusive a dominante, por sua qualidade e domínio dos gêneros literários reconhecidos pelo cânone acadêmico. A presença de índios ${ }^{7}$ nas universidades do norte do continente consolida a presença de sua literatura através de cursos de literatura indígena e de escritores e acadêmicos indígenas (Momaday, ele mesmo, lecionou na Universidade de Stanford, na Califórnia e O’Brien é professora de história na Universidade de Minnesota) que, versados nas teorias críticas ocidentais contemporâneas, refletem sobre a imagem do índio na literatura não indígena e seus estereótipos; sobre a literatura produzida por escritores indígenas, sua recepção e público alvo; ao mesmo tempo em que oferecem uma crítica que constitui um contra discurso tão relevante que pode ser lido como uma "teoria vermelha". A expressão alude ao título do livro de Graig Womak (Creek/Cherokee), um dos críticos indígenas mais radicais, e seu livro Red on red (1999), que conclama a uma "autodeterminação literária" dos autores indígenas estadunidenses (p. 1), uma vez que já “é possível ministrar cursos sobre literatura e crítica com textos de autoria exclusivamente indígena" (p. 10) ${ }^{8}$. Este chamamento já fora feito pela

7 Os termos Native American e First Nations, usados respectivamente nos Estados e Unidos e Canadá constituem uma terminologia política instituída para designar os povos indígenas em questões de reconhecimento, direitos humanos, concessão de terras, entre outros, de forma coletiva. Os povos indígenas preferem se identificar por suas afiliações tribais, aqui registradas entre parênteses. Os indivíduos indígenas costumam usar o termo "índio" para se referirem a si mesmos ou a outros índios e entre os jovens índios urbanos é comum a designação skin (como os afrodescendentes usam "brother”, por exemplo).

8 Como as obras mencionadas não têm tradução para o português, optei por parafrasear ao invés de traduzir, destacando entre parênteses expressões e definições relevantes ao assunto deste texto. 
Pontos de Interrogação, v. 4, n. 2, jul./dez. 2014

Revista do Programa de Pós-Graduação em Crítica Cultural

Universidade do Estado da Bahia (UNEB), Campus II — Alagoinhas — BA

escritora Paula Gunn Allen (Sioux), em um livro de ensaios críticos e ementas de cursos acadêmicos sobre literatura indígena, Studies in American Indian literature (1983). Em um dos ensaios, Allen analisa as dificuldades de lecionar literaturas não ocidentais a uma audiência familiarizada com os termos "primitivo", "selvagem", "pagão" e "folclórico" (p. 3).

"Vermelha" é a palavra escolhida por Womack justamente para evitar o equivocado e homogeneizador "índio" e por carregar a marca da resistência à representação do indígena na literatura euro-americana. O escritor se rebela contra os tipos de "inclusão colonial" das literaturas indígenas nos programas acadêmicos sob denominações como "étnica", em cursos de largo espectro comparativo, desconsiderando suas especificidades tribais. Ou "multicultural", onde um autor indígena pode ser lido ao lado de Amy Tam e Ralph Ellison, todos alinhados sob "as mesmas malditas citações de Bakhtin [...], reduzindo os estudos literários a pouco mais do que uma versão acadêmica do melting pot (1999, p. 8). Para ele, "o nativo e o nãonativo estão sempre desconstruindo um ao outro" e por isso a literatura indígena faz muito "para legitimar a experiência tribal como um tema literário e, principalmente, para assumir que a vida tribal vai continuar a existir no futuro" (p. 3). Para Womack a literatura norteamericana e a literatura indígena formam dois cânones separados e "as literaturas tribais não são um ramo do tronco principal, mas como as literaturas mais antigas das Américas, elas são o cânone" (p. 7).

O escritor canadense Thomas King (Cherokee), declara o termo pós-colonial inaceitável em relação às literaturas indígenas. Ele chama o triunvirato - pré-colonial, colonial e póscolonial - de "etnocentrismo não disfarçado" e "desconsideração bem intencionada". King coloca o problema do termo em seu "inescapável nacionalismo" e na "perigosa crença de que o ponto de partida de qualquer discussão é a chegada dos europeus à América do Norte". Ele completa, acusando os estudos pós-coloniais de organizarem a literatura progressivamente, “com a implicação de progresso e desenvolvimento", e de assumir que "o catalisador para a literatura indígena é a luta entre opressor e oprimido". Segundo King, a literatura pré-colonial não tem qualquer relação com a literatura colonial, "não fazem parte de um ciclo natural ou biológico, nem uma antecipa a outra". Assim, as literaturas indígenas contemporâneas não podem ser classificadas como pós-coloniais “pelo fato óbvio de que não há um 'pós' ao status colonial dos indígenas norte-americanos" (1997, p. 242). 
Womack destaca o papel cada vez mais importante que as tribos e seus membros devem ter na avaliação das literaturas tribais. Um dos temas mais importantes dentro da literatura indígena é justamente esta afiliação tribal, prática adotada por todos os escritores indígenas. $\mathrm{O}$ Louis Owens (Choctaw/Cherokee), acadêmico fluente nos discursos ocidentais do pósmodernismo e do pós-colonialismo, reconhece que essa "rearticulação" de uma identidade é "uma tarefa enorme" e central à ficção indígena, devido a obstáculos que ele chama de "invenções" do índio Americano na imaginação coletiva e a noção de que esta figura desapareceu há muito tempo e foi substituída pelo autóctone atual e sua experiência contemporânea. Desse “descompasso entre mito e realidade" surge a maior parte da arte indígena (1992, p. 5).

Para Owens, a questão do gênero literário também é importante, pois um poeta indígena ainda consegue ver-se como parte de uma antiga tradição oral de contadores de história, enquanto o romancista autóctone trabalha sem protótipos indígenas, com a consequente "dessacralização" do material tradicional e sua "descontextualização" dentro do mundo da arte ou da literatura (1992, p. 11). Segundo Owens, o romancista autóctone precisa superar traços de uma "etnostalgia rousseauista" comum ao tratamento do indígena em romances euroamericanos. O resultado positivo desta estratégia é a colocação subversiva do leitor indígena em uma posição privilegiada, enquanto o leitor não-indígena passa a ser o “outro" (p. 14). Ao apropriar-se da "outra língua", o escritor indígena está "entrando em diálogo com o próprio idioma do colonizador" (p. 15).

Elizabeth Cook-Lynn (Crow/Creek/Soiux) reforça a importância da filiação tribal, pois ela vê como tarefa do escritor indígena mitificar a sua relação com o espaço e lutar contra um cânone onde "a morte e o enterro de sua presença é tão explícita" e encontrar formas de "fazer a reconciliação necessária com a continuidade e a historiografia primordial” (1996, p. 33). Ela considera um erro de certos escritores indígenas pensarem que é possível se tornarem "cosmopolitas, híbridos, ou mesmo exóticos com impunidade" (p. 84). Cook-Lynn indica o romance Almanac of the dead (1991), de Leslie Marmon Silko (Laguna/Pueblo), como um exemplo de "pantribalismo nacionalista ficcional" por retratar de forma assertiva a luta pela posse de terras retiradas das tribos durante o período colonial e por difundir a ideia "de que a imaginação tem um papel funcional na vida política e social, uma ideia que a maioria dos tradicionalistas indígenas que conheço abraçam” (p. 89). 
Gunn Allen acrescenta que o objetivo da literatura indígena não é puramente a autoexpressão, mas através dos cantos, lendas e histórias sagradas, incorporar, articular e compartilhar realidades, "sentir dentro de si o conhecimento comunitário da tribo" (1983, p. 4).

Cook-Lynn, como Allen e muitas outras escritoras, defendem o papel central da mulher indígena nas culturas tribais. Para Allen, "as raízes do feminismo branco tem raízes vermelhas" (1988, p. 13). Não reconhecer sua mãe, segundo ela, é a incapacidade de lembrar seu significado, sua realidade, sua relação correta com a terra e a sociedade. "É a mesma coisa que estar perdida - isolada, abandonada, estranha e alienada de sua própria vida” (p. 14). Ela vai além e declara que se as tradições autóctones tivessem sido seguidas, "o lugar da mulher na sociedade seria central, a distribuição de riqueza e do poder seriam igualitárias, os idosos seriam respeitados, homenageados e protegidos como uma fonte social e cultural primária, os ideais de beleza física seriam consideravelmente mais amplos [...] a destruição do bioma, a esfera de vida e os recursos naturais do planeta seriam poupados e a natureza espiritual da vida humana e não humana se tornariam o princípio organizacional da sociedade humana" (p. 15). Para ela, os norte-americanos resistem ao conceito de "indianização", mas ela aconteceu e está na raiz dos valores pessoais, familiares, sociais e políticos (p. 23). Um dos exemplos de indianização mais citados é a consagrada democracia estadunidense, que segundo especialistas, seria modelada na Confederação Iroquesa.

Gerald Vizenor (Anishinaabe), como tantos indígenas atualmente, descende de índio e euro-americano e seu trabalho explora o que isso significa no mundo contemporâneo, definindo-os como sujeitos crossblood. Para ele o termo "não possui validação social ou científica (como mulato ou mestiço) porque não é uma medida de consciência, cultura ou experiência humana", mas define aqueles que, como ele, "mergulham em cantos urbanos desconhecidos, na escuridão racial das cidades, para criar uma nova consciência de coexistência" (1981, p. ix).

Duas de suas obras não ficcionais, Crossbloods (1990) e Manifest Manners (1999), criticam tanto o nacionalismo autóctone quanto as atitudes coloniais dos euro-americanos. Como bom leitor de Derrida, Vizenor revisita a discussão sobre "índio" ser um termo inventado pelos "invasores europeus": "antes do primeiro desembarque de Colombo não havia "índios", mas povos de varias tribos, como os Anishinaabe ou Dakota. A expressão manifest manners 
refere-se ao legado do Manifest Destiny ${ }^{9}$, ou a forma como os autóctones continuam amarrados a narrativas de dominação que os troca por “índios”. No lugar desse significante genérico ele sugere que os povos sejam referidos pelo nome de suas tribos e sempre que possível, colocados em seu contexto tribal específico. Para discutir estudos indígenas mais gerais, Vizenor propõe o termo pós-índio, que dá uma ideia da heterogeneidade das culturas tribais. Para descrever a experiência dos pós-índios, ele introduz a expressão survivance, uma combinação de sobrevivência com resistência, por carregar a implicação de um processo em andamento ao invés de simples continuação e aponta para a natureza política da literatura indígena.

Os personagens de Vizenor acreditam em mediação, segundo as culturas tribais, onde há uma busca por equilíbrio do homem entre outros homens e na natureza. Para o escritor, o objetivo cristão de livrar o ser, a alma, a comunidade de todo o mal, é tão enraizada na consciência norte-americana que é expressa no discurso - guerra contra pobreza, guerra contra a ignorância e a selvageria - e o objetivo é destruir o inimigo completamente. A isso Vizenor denomina terminal creed, ou seja, a crença de que o fim de um conflito se dá com o triunfo definitivo de um absoluto.

Estas crenças, Vizenor se dispõe a desconstruir com humor, ironia e uma linguagem que se recusa a enunciar significados absolutos. Assim sendo, sua arte tem como fonte o humor indígena e a figura do trickster, dois dos traços mais difundidos a unificar as culturas tribais norte-americanas. Seus tricksters pós-índios representam estranhos atos de desconstrução do discurso literário estadunidense, e são uma metáfora perfeita para as contradições existentes entre as duas cosmogonias.

O trickster Anishiinabe, oriundo dos mitos de criação, é compassivo, "aquele que cuida de equilibrar o mundo entre crenças terminais e humor com maneiras incomuns e estratégias entusiastas". E também fala uma nova linguagem, uma vez que "suas experiências e sonhos são metáforas" (1981, p. xii). A linguagem que usa pode parecer tão incomum que se des-

9 A expressão, popularizada por John Louis O’Sullivan em 1845, está relacionado tanto à luta contra a escravidão sulista quanto à vasta e cruel diáspora interna a que foram submetidas os autóctones durante a expansão do país até o Pacífico. Vizenor introduz um jogo irônico com os "pais da nação" e o conceito de Manifest Destiny, popular no século XIX, de que os colonos americanos estavam destinados a se expandirem por todo o continente. O termo "manifest manner" teria se originado de uma piada sobre um presidente de universidade que encorajava estudantes a cumprimentarem estudantes de minorias nos corredores para que se sentissem integrados. 
Pontos de Interrogação, v. 4, n. 2, jul./dez. 2014

Revista do Programa de Pós-Graduação em Crítica Cultural

Universidade do Estado da Bahia (UNEB), Campus II — Alagoinhas — BA

mancha, mas é só uma ilusão de desintegração "porque não leva ao silêncio" (1981, p. xvii). "Nas metáforas, certas palavras tomam sentidos novos, ou ampliados". Os tricksters métis são eles próprios "as novas metáforas entre as culturas tribais comunitárias e culturas que se opõem a conexões tradicionais, as culturas que se apossariam e comercializariam a terra" (1981, p. xvii). Acima de tudo, os personagens de Vizenor são mediadores, nunca vítimas.

O coiote nas histórias de Thomas King, também é um personagem que toma várias formas humanas e animais, e por vezes pode ser fêmea, prega muitas peças e mostra inapelável bom humor. Como o trickster de Vizenor, ele age como um mediador entre a cultura indígena e a ocidental, entre índios imersos em suas culturas e índios aculturados; através de sonhos, danças, peidos, ele tenta "endireitar" o mundo, ou partes dele. Outra figura recorrente das “coyote stories" de King é Primeira Mulher, memorável por "reencenar" a criação do mundo do ponto de vista nativo. "Primeira Mulher trata todos os homens, Deus, Adão ou Noé, como meninos, que por serem lentos, birrentos ou assanhados, precisam de condescendência $\left(\right.$ SANTOS, 2007, p. 204) ${ }^{10}$.

Tomson Highway, premiado dramaturgo canadense, funda em 1996 um Comitê para o Restabelecimento do Trickster, juntamente com Lenore Keeshing-Tobias e Daniel David Moses. Em suas peças de teatro Dry lips oughta move to Kapusaking (1989) e Rose (2003), Highway nos apresenta uma trickster configurada a partir das culturas Cree e Ojibway, onde o uso da língua Cree cria um diferencial que obriga ao leitor a usar as traduções para o inglês no rodapé dos livros, mas expõe os espectadores das montagens a um esforço maior de compreensão destas outras línguas e culturas. Como fez Arguedas, no Peru, com seu romance El zorro de arriba y el zorro de abajo (1971), eivado de quéchua, que altera o castelhano de forma substancial, em um exercício de apropriação da forma escrita e ao mesmo tempo de resistência, através do que Alberto Moreiras chama de "implosão do significado" (2001). As duas obras denunciam a opressão e a violência contra as mulheres indígenas, a de Highway encenando inclusive uma violenta cena de estupro. Sua montagem mais recente, The (post) mistress (2010), um musical com uma única artista, encenado em Cree (“a língua do trickster”,

${ }^{10}$ Sobre o trickster, indico a leitura de Arnold Krupat, Para entender os trickster tales dos nativos norteamericanos. Trad. Eloína Prati dos Santos. In: SANTOS, Eloína, (Org.), Perspectivas da Literatura Ameríndia no Brasil, Estados Unidos e Canadá. Feira de Santana: UEFS, 2003, p. 15-40 e de Rubelise da Cunha, Anti-colonial tricks: story telling figures of resistance in Lee Maracle, Thomas King and Tomson Highway (Tese de Doutoramento, PUCRS, 2005). 
em Toronto, aborda temas como Aids, abuso sexual, pobreza e racismo nas comunidades nativas (JOHNSON, 2013, online).

Lee Maracle (Salish/Cree) é uma das mais prolíficas escritoras canadenses, ativista do Red Power Movement e do Liberation Support Movement e crê que "a acumulação de pesares" dos povos indígenas vem de longo tempo. “Às vezes me sinto como uma avó tola, armada de uma colher de chá, determinada a remover as três montanhas do caminho da liberação: a montanha do racismo, a montanha do sexismo e a montanha da opressão nacional" (1996, p, x). Uma das formas de fazer isso, para ela, é a autoficção, que lhe permite examinar as condições de vida da mulher indígena desde "um lugar profundamente pessoal" (p. xi), explícito em I am woman (1996), onde a alternância entre poesia e prosa nos aproxima da oralidade das narrativas indígenas.

A questão da mestiçagem e a história de opressão contra as mulheres indígenas é examinada ainda pela canadense Janice Acoose (Sakimay), que, como Owens e Vizenor, ostenta com orgulho o termo mestiça, baseada no famoso romance autobiográfico de Maria Campbell, Halfbreed (1973), um livro sobre ser métis, audacioso para a época. Acoose analisa a "elevação" de mulheres que mantiveram relações com cristãos brancos: Dona Marina, a Asteca que teve uma ligação com Hernando Cortez; Pocahontas, que salvou John Smith e seus homens da morte ao guiá-los por terras indígenas; e também oferece várias ilustrações do Novo Mundo representando "mulheres com aspecto real" e "mulheres majestosas com arco e flecha" e pouca roupa. Depois do período colonial, elas passaram a squaws, ou mulheres indígenas de má reputação, para justificar o expansionismo imperial e as agendas missionárias, bem como para satisfazer o apetite sexual de comerciantes de peles e exploradores. Acoose cita documentação abundante da história e da literatura euro-canadense sobre a sobrevivência desse estereótipo até nossos dias (1995, p. 44-45). Segundo ela, isso contribui para "perpetuar a violência sexual, física, verbal e psicológica" contra as mulheres indígenas. Até hoje elas precisam lutar contra uma combinação de racismo e sexismo, legal e politicamente, enquanto reivindicam seu papel central como guardiãs da cultura e autonomia sobre seus corpos (p. 58).

Como prova da injustiça da permanência desse estigma, Acoose percorre uma lista de autoficções de mulheres indígenas canadenses que a precederam: Emma LaRoque, Beatrice Culleton, Jeanette Armstrong, Lee Maracle, Ruby Slipperjack, Marie Anneharte Baker, Beth Cuthand, Louise Halfe, Patricia Monture-Okanee, Monica Goulet, Marylyn Dumont, Mary 
Pontos de Interrogação, v. 4, n. 2, jul./dez. 2014

Revista do Programa de Pós-Graduação em Crítica Cultural

Universidade do Estado da Bahia (UNEB), Campus II — Alagoinhas — BA

Sky Blue (p. 39), uma lista de "mulheres que sobreviveram para contar suas histórias e encontram solidariedade e conforto entre suas irmãs” (p. 104). Elas compõem, com vários outros nomes, uma lista que corrobora a visão de Womack e Allen sobre a possibilidade de se ministrar um curso exclusivamente sobre autobiografia e mulher indígena no Canadá, assim como nos Estados Unidos, ao mesmo tempo em que afirma a validade de usar a língua inglesa para representar suas experiências, renomear e redefinir seus povos originais (p. 58).

$\mathrm{Na}$ academia brasileira, as literaturas indígenas aparecem escassamente, incluídas em cursos como Literaturas de Língua Inglesa ou Literatura Pós-colonial, analisadas de forma fragmentária e sob uma visão insistentemente pós-colonial. Os autores indígenas brasileiros raramente escapam da classificação de literatura infanto-juvenil, mas legislação recente oferece a oportunidade de introduzi-la nas escolas de forma mais consistente.

A partir do final da década de 1980, os indígenas brasileiros começam a obter reconhecimento através de obras sobre suas culturas e mitos e podemos reconhecer dezenas de autores indígenas com trabalhos relevantes publicados. Como aponta Daniel Munduruku, "é importante dizer que estamos conquistando espaço não porque somos 'exóticos', mas porque escrevemos bem"11.

Eliane Potiguara é escritora, poeta, e ativista pelos direitos indígenas há 30 anos, uma das mulheres indígenas com uma educação de nível superior no Brasil e toda sua rica vivência encontra-se elaborada em Metade cara, metade mascara (2004), sob várias formas narrativas — testemunho, poesia, autobiografia, ficção — que se entrelaçam para recuperar errâncias físicas e intelectuais, a luta por autoestima e pela manutenção de sua tradição cultural, e pela recuperação da identidade e da dignidade da mulher indígena, na mesma linha seguida pela maioria das escritoras norte-americanas e canadenses aqui mencionadas. O livro de Potiguara se assemelha em estrutura a I am woman, de Lee Maracle, por exemplo ${ }^{12}$.

As vozes e as experiências que o livro de Potiguara reúne são da tradição oral de seu próprio povo, transmitidos pelas histórias de sua avó e através de visitas à sua Paraíba natal.

11 Disponível em: www.almanaquebrasil.com.br/index.php?option=com_content\&view=article\&id=10634:dan iel-munduruku\&catid=12956: cultura\&Itemid=168 - 54k. Acessado em 22/02/2012.

12 Come on, Sister, de minha autoria (p. 47-62), e Writers and storytellers, Lee Maracle and the consolidation of Indigenous Literatures in Canada and Brazil (p. 63-82), de Rubelise da Cunha, são artigos que comparam a obra de Potiguara à das escritoras canadenses Acoose e Maracle. Interfaces Brasil/Canadá, v. 12, n. 15, UFF e Centro Universitário La Salle, 2012. 
Mas também de Kaiapós e de Charruas uruguaios, que ela conheceu através de seu esposo, o cantor popular de origem Charrua, Taiguara.

O livro é curto, tem 138 páginas, mas cobre quinhentos anos de desastroso contato entre índios e brancos no Brasil. Começa por recuperar a história das primeiras invasões de território indígena em tempos modernos, as neocolonizações da mineração, da abertura de estradas, das queimadas para pastagens, a consequente migração indígena, a separação das famílias, a violência, o racismo, a intolerância, com as mulheres como as maiores vítimas. A avó de Eliane, conforme ela nos relata, foi uma dessas vítimas e, separada do pai de seus filhos, vendeu bananas nas ruas da cidade para sustentá-los. Eliane foi a primeira mulher da família a ser educada e a emergir da pobreza, tornando-se uma professora primária apaixonada pelos conceitos de educação popular de Paulo Freire.

Chama a atenção que o "mundo possível" de Potiguara também proponha uma utopia em um mundo tão conturbado. A visão utópica faz parte da visão poética do mundo, inerente às culturas ameríndias. Se o resgate de suas culturas já não pode ser feito de forma real, ele nunca deixou de existir nas narrativas tradicionais.

O livro de Potiguara, como de Acoose e outras autoficções de mulheres indígenas, desafia classificações: não é um romance, embora encerre a história de Jurupiranga e Cunhataí; não é autobiografia, embora relate leituras, errâncias, aprendizados, ideias, memórias da autora que se confundem com os de sua avó e de seu álter ego, Cunhataí; não é um livro de poemas, mas há vários deles entrecortando uma narrativa também poética. Não é um livro panfletário, mas faz uma defesa intransigente dos direitos indígenas neste país, das mulheres em especial e dos oprimidos do mundo em geral, e conclama a mudanças radicais. Ele amplia o panorama da situação sócio-política dos índios no Brasil para uma dimensão literária onde ele pode ser resolvido, como em sua proposta das "aldeias de amor". Metade cara, metade máscara é ainda pós-canônico, pois insere a voz ameríndia na literatura indianista nacional e desnuda um ponto de vista alternativo ao dos escritores não indígenas sobre o encontro colonial e pós-colonial entre as etnias fundadoras da cultura brasileira, inclusive por seu alinhamento com os movimentos negros. A inserção desse tipo de texto em nossos cursos de literatura brasileira amplia o conceito de literatura brasileira e o próprio conceito de "romance", bem como a percepção de nossa herança cultural. Como destaca Eurídice Figueiredo, em um capítulo que reúne Potiguara e Conceição Evaristo, "Em vez de uma nação homogênea, criada pelos 
intérpretes do Brasil, que excluía negros e indígenas ao diluí-los no amálgama chamado "Brasil mestiço", o que vemos agora é a eclosão de vozes que narrativizam outras histórias, outras versões sobre a nação". E acrescenta, "Por conseguinte, aflora um contingente de escritores que reivindica um pertencimento marcado pela etinicidade" (p. 152).

Munduruku, com cerca de 40 obras publicadas, é considerado um dos mais influentes escritores da atual literatura indígena no Brasil. Formado em filosofia, com licenciatura em história e psicologia, foi um dos primeiros índios a obter um doutorado no país. Doutor em educação pela Universidade de São Paulo (USP), ele não hesita em afirmar que a escola brasileira ainda reproduz uma visão meticulosamente construída pelos colonizadores no século 16, responsável pelo preconceito contra os índios, o que justifica o engajamento político da literatura indígena no Brasil ${ }^{13}$.

Suas Histórias de índio (1996) abordam os vários encontros entre paulistas de todas as idades com esse estranho que é o índio brasileiro urbano, revelando um cotidiano de desconhecimento, indiferença e preconceito, que Munduruku combate com ironia, bom humor e didatismo. O índio urbano está presente em $80 \%$ dos municípios brasileiros e Munduruku oferece uma contribuição importante para subverter os resquícios de romantismo sobre os povos nativos que ainda prevalecem em nossa cultura e demonstram o quão colonial ainda é nossa visão da interracialidade brasileira, onde para a maioria dos brasileiros, índio é aquele que ainda vive na selva uma vida pré-cabralina.

Considero o romance, O Karaíba, uma história do pré-Brasil (2010), uma obra de grande importância por nos fazer retroceder a antes do encontro entre europeus e ameríndios e adentrar um universo de histórias ancestrais que pretendem recriar a era pré-cabraliana ignorada pela teoria ocidental. Como diz o Karaíba "é preciso conhecer o passado para entender o presente e sonhar o futuro" 14 O livro mergulha na vida de três grupos indígenas que vivem segundo suas crenças, costumes e rivalidades em um Brasil sobre o qual, no entanto, paira a imagem de seres distantes, desconhecidos e temidos. Entre os personagens de Karaíba, há uma preocupação com a descendência, com a captura de esposas em outras tribos, evitando a consanguinidade, com a preservação da tribo, preparação para a guerra com as outras tribos

\footnotetext{
13 Da mesma entrevista da nota 1.

14 Orelha da obra, redigida por Munduruku.
} 
ou grupos, em ouvir os mais velhos e sábios, interpretar as previsões místicas e sonhos que retratam costumes ancestrais. Também há sinais de uma inescapável contemporaneidade em suas figuras centrais: Perna Solta é poupado da morte por seu defeito físico, enquanto o pai de Potyra permite que ela torne-se uma guerreira, flexibilidades que poderiam significar um fim trágico nas comunidades na época. Essa humanização do índio na sua flexibilidade, responsabilidade social e afeição a seus familiares, demonstram um cuidado em não mostrar os índios como "selvagens" antes da chegada dos europeus e de promover a desconstrução da tradicional figura do imaginário euro-americana que persiste no imaginário contemporâneo.

Os três grupos rivais que povoam o romance, determinados, a lutar uns contra os outros, acabam convergindo para uma clareira por terem interpretado de forma equivocada a mesma profecia do Karaíba, o sábio e profeta respeitado por todos. O motivo da reunião dos líderes é a de anunciar a eles "tempos difíceis".

A filosofia indígena de cooperação, descrita em Karaíba como o encontro final dos três grupos na clareira nos remete à Confederação dos Tamoios (1556-1567), por exemplo, liderada pelos Tupinambás e por um período pelo próprio Cunhambembe, e por certo é uma crítica à exterminação dos povos indígenas brasileiros, através da qual os portugueses se inscreveram na história das "crenças terminais" que Vizenor descreve.

Em seu breve posfácio, Munduruku deixa a seus leitores tarefa de completar a história que "termina quando começa o relato por parte dos invasores" (p. 95), aqueles que descreveram os indígenas brasileiros como "selvagens, atrasados, desorganizados, canibais e preguiçosos" (p. 95). Essas afirmações a obra rebate ao mostrar os indígenas como leais, corajosos, organizados em comunidades que viviam em harmonia com a natureza circundante, respeitadores de seus líderes e de suas tradições, seres humanos que guerreavam, amavam, odiavam, tinham inveja, ciúme, compaixão.

Percebe-se neste livro novamente uma inversão muito linear da visão popular do indígena, mas o mais notável é a presença constante do "fantasma" do europeu na narrativa. Por um lado explica-se pelo colapso temporal típico da oralidade tribal, em que passado, presente e futuro coexistem e se contaminam. Por outro, revela esse índio contemporâneo, que tenta inserir sua voz na cultura hegemônica recriando um tempo anterior ao contato com o europeu e ao mesmo tempo reafirmando a violência do processo colonial, sua irreversibilidade e a per- 
Pontos de Interrogação, v. 4, n. 2, jul./dez. 2014

Revista do Programa de Pós-Graduação em Crítica Cultural

Universidade do Estado da Bahia (UNEB), Campus II — Alagoinhas — BA

petuação dos equívocos nascidos dos primeiros contatos e profundamente disseminados na cultura brasileira contemporânea e muitas das reflexões pós-coloniais sobre o assunto.

Além do mais, essa tentativa de recriar tempos pré-coloniais me parece rara, se não inédita, na literatura indígena das Américas, e busca combinar a narrativa contemporânea com a mítica das culturas indígenas. A obra de Munduruku, ao mesmo tempo em que reafirma todo o pesadelo do processo colonial para os indígenas, deixa claro o sonho de reconhecimento de sua resistência inabalável e de sua significativa contribuição para uma cultura que os desconhece a não ser como figura mítica, tornando invisíveis suas demandas por integração completa ao Brasil contemporâneo.

Os escritores indígenas nos oferecem uma oportunidade de revisar a visão estática da figura do indígena, suas culturas e suas vidas no mundo contemporâneo e o fazem nos termos das ideias e pontos de vista indígenas conforme elas evoluíram até a atualidade. Este ponto de vista deveria ser uma novidade animadora para o leitor não indígena, pois representa a reintrodução de uma mitologia milenar americana, ignorada nos estudos literários, dominados pelo conhecimento da mitologia greco-romana e europeia. Em tempos de preocupação com o futuro do planeta, de preservação do meio ambiente, as literaturas indígenas são muito atuais por mostrarem preocupações holísticas e ecológicas de convivência entre a humanidade e os demais elementos, em situação de igualdade de valores essenciais e responsabilidade pelo mundo que habitamos. Essa visão, desmantelada e eclipsada pelo processo colonial, ainda circula no continente, viva e preservada e é — sem dúvida enriquecedor — trazê-la para competir com o cânone euro-americano.

É animador pensar na abundância e na qualidade da literatura ameríndia e na mudança de paradigma que aos poucos se torna evidente. A partir do ano 2000 é notável o número de obras originais, de grande fôlego que revisitam a história colonial brasileira e onde personagens indígenas têm grande destaque. Meu querido canibal (2000), de Antônio Torres, Nove noites (2002), de Bernardo Carvalho, O rastro do jaguar (2008), de Murilo Carvalho, Órfãos do Eldorado (2008), de Milton Hatoum, Meu destino é ser onça (2009), de Alberto Mussa, Yuxin (2009), de Ana Miranda. E Metade cara, metade máscara (2005), de Eliane Potiguara e Todas as coisas são pequenas, de Daniel Munduruku (2007), que assinalam a chegada da autoria indígena ao romance nacional. Cada vez mais complexos, os romances indianistas da atualidade recorrem a formas originais de revisitar a história do período colonial brasileiro, 
algumas das quais esgarçam as próprias definições tradicionais de romance e superam tanto o romance histórico como a paródia em seu uso da história e de seus fragmentos preservados por escrito.

Mais animador ainda é ver indígenas brasileiros, como Munduruku e Graça Graúna publicarem suas teses de doutoramento sobre assuntos indígenas, ele sobre educação dos povos indígenas, ela sobre a literatura indígena contemporânea. E cada vez mais acadêmicos brasileiros de variadas áreas do conhecimento publicando e ensinando sobre nossos povos nativos, uma colaboração inter-racial que pode auxiliar no resgate da memória destes brasileiros que estão ao nosso lado e que, no Brasil em especial, ainda têm um longo caminho a andar em direção a uma democracia racial que deveria ter começado a se construir a cinco séculos.

\section{REFERÊNCIAS}

ACOOSE, Janice. Iskwewak Kah Ki Yaw Ni Wahkomakanak. Neither Indian princess nor easy squaw. Toronto: Women’s Press Suit, 1995.

. A biography. Disponponível em http://www.research2.csci.edu.ubc/ca/indigenation/ Indian_ReACTions/MariaCampbell.htm.k. Acesso em Nov, 2014.

ALLEN, Paula Gunn. Studies in American Indian literature. New York: MLA, 1983.

. Who is your mother? Red roots of white feminism. In Multicultural literacy. Rick Simonson, Scout Walter, Eds. Saint Paul: Greywolf Press, 1988.

The sacred hoop: recovering the feminine in American Indian traditions. Boston: Beacon Press, 1986.

FIGUEIREDO, Eurídice. Mulheres ao espelho: autobiografia, ficção, autoficção. Rio de Janeiro: Eduerj, 2013.

HIGHWAY, Tomson. Dry lips oughta move to Kapusaking. Calgary: Fifth House, 1989. . Rose. Vancouver: Talon Books, 2003.

JOHNSON, Julia de Laurentis. In conversation with Tomson Highway. Maclean's, 30/9/2013. Disponível em http://www.macleans.ca/culture/in-conversation-with-tomson-highway. Acesso em 14/12/2014.

KING, Thomas. Godzilla vs post-colonial. In New concepts of Canadian criticism. Ajay Heble, Palmateer, Donna Pennee, and J.R. Struthers, Orgs. Ontario: Broodview Press, 1997.

MARACLE, Lee. I am woman: a Native perspective on sociology and feminism, Vancoucer: Press Gang, 1996.

MOREIRAS, Alberto. A exaustão da diferença. A política dos estudos culturais latinoamericanos. Trad. de Eliana Lourenço de Lima Reis e Gláucia Renate Gonçalves. Belo Horizonte: EDUFMG, 2001. 
MUNDURUKU, Daniel. Todas as coisas são pequenas. São Paulo: ARX, 2008. 2009.. Histórias de índio. São Paulo: Companhia das Letrinhas, 1996.Rio de Janeiro: Record,

O Karaíba. Uma história do pré-Brasil. Barueri, SP, Manole, 2010.

MURRAY, Laura. Review of looking at the words of our people, by Jeannette Armstrong. Disponível em http://www.utpjournals.com/product/utp/651/wrods26.html. Accesso em Nov. 2014.

SANTOS, Eloína. A criação do mundo Segundo Thomas King: uma performance visionárioliterária. In: Performances. Orgs: Luiz Paulo de Moita Lopes, Fábio Ackelrud Durão e Roberto ferreira da Rocha. Rio de Janeiro: Contra Capa, 2007, p. 201-215.

OWENS, Louis. Other destinies. Norman: University of Oklahoma Press, 1992.

POTIGUARA, Eliane. Metade cara, metade máscara. São Paulo: Global, 2004.

VIZENOR, G. Survivance: Narratives of Native Presence, edited essays, University of Nebraska Press, 2008.

. Manifest Manners: Narratives of Postindian Survivance, Preface to a New Edition, University of Nebraska Press, Lincoln, 1999.

Shadow Distance: A Gerald Vizenor Reader, autobiography, fiction, stories, essays, and other selections, Wesleyan University Press, 1994.

Crossbloods: Bone Courts, Bingo, and Other Reports, a collection of essays, University of Minnesota Press, Minneapolis, 1990. 1983.

Earthdivers: Tribal Narratives on Mixed Descent, University of Minnesota Press,

WOMACK, Craig S. Red on Red. Native American Literary Separatism.Minneapolis, London: University of Minnesota Press, 1999.

Recebido em: 19 de outubro de 2014.

Aceito em: 20 de novembro de 2014. 
